psychiatrically naive but know their local communities well. Second that rural populations are quite capable of making appropriate self referral, although the curiosity factor ("let's see what the new doctor is like?') may waste a certain amount of time and some of the most ill patients may be missed. It is really not very different in the allegedly developed world.

Royal South Hants Hospital

C. M. H. NuNN

Southampton SO9 4PE

Reference

SIDANDI, P. (1990) Rehabilitation psychiatry: description of a provincial setting in Zimbabwe. Psychiatric Bulletin. $14,552-554$.

\section{Archibald Campbell Clark}

DeAR SIRS

If any of your readers knows of the whereabouts of an authentic portrait or photograph of Archibald Campbell Clark (d. 1901) I should be grateful if they would let me know. I am aware of the portrait plaque on the Pinel Memorial at the Royal Edinburgh Hospital. The information is required for a history of Hartwood Hospital of which Clark was the first Physician Superintendent.

JuLIAN Hodgson Librarian

Hartwood Hospital

Hartwood, Shotts

Scotland ML7 4LA

\section{Deaf patients at Rampton Hospital}

DEAR SIRS

Since Dr Roberts' pioneering work in establishing the group for deaf patients at Rampton Hospital (Psychiatric Bulletin, May 1990, 14, 279-282) it is pleasing to be able to report further developments.

Firstly, the Deaf Group as described by Dr Roberts continues to thrive and now forms a social club which meets fortnightly. Voluntary visitors who are also deaf join the group, forming an important source of contact with the local community and enhancing the development of deaf culture within the hospital. The hospital interpreter is now employed three days a week assisting staff in all departments in their communication with deaf patients. For example, the interpreter attends case conferences and ward reviews and is involved with staff in individual patient counselling sessions.
The hospital has recently employed a Sign Demonstrator who is also deaf. The Sign Demonstrator works principally for the Education Department, assisting the teaching staff in their daily classes with the deaf. The Sign Demonstrator is seen as an important role model for deaf patients, serving to remind them that they too can achieve in a predominantly hearing world.

Increasing staff awareness has led to a call for further education and training. This has been met by providing training workshops in 'Deaf Awareness' and these have been run in conjunction with the Royal National Institute for the Deaf. A number of such training events have been held in the hospital and have been attended by staff from many disciplines. There have also been training days for deaf patients in how to use an interpreter.

A significant number of staff in various disciplines are now acquiring British Sign Language (BSL). Classes are currently being run in the hospital by the Sign Demonstrator. A number of staff are now at Stage II of the CADCP. The services of a speech therapist are also available to patients with hearing impairments.

This list is not exhaustive. Attention is being paid to the use of hearing aids, Teletext televisions, minicom telephone communications etc. A Steering Group for the Deaf, which was established around the time of the initial group meetings, monitors developments within the hospital. Currently attention is being focused on the hard of hearing.

In conclusion the formation of the Deaf Group and the lessons learnt from it have not fallen on deaf ears.

Rampton Hospital

EMMET P. LARKIN

Retford, Notts DN22 OPD

\section{Psychiatry in bookshops}

\section{DEAR SIRS}

I was interested to read Dr Watts' letter (Psychiatric Bulletin, October 1990, 14, 630), in which he suggests we might take note of where bookshops choose to market their books on psychiatry.

In the medical library at the Towers Hospital, Leicester, Ellis \& Calne's Lecture Notes on General Surgery has languished for many years in the section on Sexual Deviations. I am told this is an artefact of the classification, not a librarian's parapraxis.

Carlton Hayes Hospital

Christopher MAloney 